honorary plague officers should be appointed in all districts subject to infection (paragraph 50).

(23) The submission, by commissioners to the Inspector-General of Civil Hospitals, Punjab, of a quarterly return showing the grants-in-aid made to local bodies from provincial funds (paragraph $54)$.

(24) Rat destruction operations on the limited scale recommended by the Committee should be a charge on provincial funds (paragraph 55.)

\section{Guntent Topits.}

\section{SANITARY STANDARDS FOR WATER SUPPLIES.}

OUR readers may remember that in our January issue (I. M. G., January 1910, p. 23) we discussed at length the suggestive and valuable report on the water supplies of towns and institution in Madras which was carried out by Major W. W. Clemesha, I.M.s. (now Sanitary Commissioner in Bengal), and his assistants Assistant-Surgeons Aiyar and Mudaliyar in the King Institute. Since then Major Clemesha has commenced a similar survey of the bacteriology of the drinking water supplies in Bengal and in an admirable memorandum recently circulated to medical officers in military employ we are glad to see that Brevet-Colonel R. H. Firth, R.A.M.c. (the Sanitary Officer at Arny Head-Quarter, India, and present Editor of the current editions of what was once known as "Parkes" Hygiene") has ably discussed the question as to how far European standards of chemical and bacteriological examination of drinking water can be applied to Indian supplies. It is a matter of common knowledge that most of the waters in daily use by the people of India are quite unsuitable according to European standards, and it is equally certain that "the morbidity results are not in proportion to the conditions"; for example, wo know of jails in Bengal where there is an average high rate of good health, far above that of the surrounding population, yet the results of the chemical analyses of the drinking waters are recorded as "suspicions," " bad," or at best " usable." Of course in these cases the boiling of the water minimises any risk.

We agree with Colonel Firth that we would not go along with those who would omit as useless a chemical examination, but we recognise its limitations and we are certain that a revised standard for India is necessary. "To adopt the standards in current use in England we should have to condemn ninety per cent. of Indian waters." Local seasonal standards are the only safe guides, especially in places liable to heavy falls of rain.
The importance of the biological examination of water is becoming increasingly recognised, but we have still much to learn about the fauna and flora of Indian waters. The following three bacteriological examinations, says Colonel Firth, are essential; (1) a count of the total colonies in 1 c. c. of the water ; (2) a test in milk for sponogenes enteritiditis in not less than 20 c.c. of the water; and (3) the inoculation of a series of tubes of bile-salt broth, with various quantities of water, using a modification of Thresh's adaptation of MacConkey's method.

The question remains-Can we lay down a bacteriological standard for drinking waters in India? Can we use the B. coli as a true and workable index of bacterial purity or impurity? To reply to the latter question we must decide what we mean by a $\mathrm{B}$. coli communis. 'The term is used in an elastic sense by many English bacteriologists and many of the organisms which fall within such an elastic definition "are so common in all Indian waters that to regard their presence as indicative of fæcal contamination means the wholesale condemnation of drinking waters in constant use."

On this point we may quote Colonel Firth in full :-

"In this matter, therefore, we need to depart from English standards, recognise that while in England or Europe the bulk of the contamination of waters is due to human excrement in the form of sewage from towns, it is otherwise in India, where much of the fouling is from animals other than men. Further, that the true B. coli communis of Escherich is by no means so common as many suppose in the fæces of man and other animals in India and, inasmuch as this bacillus is a very suscep. tible micro-organism to forces of nature, inimical to bacilli generally, its presence in waters represents actually a recent and dangerous contamination. In the present scanty state of our knowledge regarding Indian waters, we are reluctant to suggest any precise numerical standard for this micro-organism, even when so closely defined as above. Tentatively, the following proposals are advanced; in a good pond, tank, or surface water, there should be no B. coli in $20 \mathrm{c}$ c. if present in $5 \mathrm{c} \mathrm{c}$. such water is suspicious, and if found in l. c. c. or less it is to be condemued. A good river water should not yield more than one colony of $\mathrm{B}$. coli in $10 \mathrm{c}$. c., but if present excess of 20 per c. c. it is suggestive of a bad river water to point of condemuation. In the case of wells or springs the working limit for a good water may be placed at no B. culi in 15 c.c. As isolated standards, these figures may be misleading and their true value can only be estimated when taken in conjunction with the nature of the other or associated micro-organisms in the sample. A more extended series of working standards will be given further on, in which the undue focussing of attention on the B. coli communis is avoided.

This brings us to the question of a rossible classifica. tion of the various lactose fractors, as isolated by the method described. It is true they are not the only group of frcal organisms, but they are undoubtedly one of the most important. For much work in this direction we are indobted to MacConkey, who suggested the division of all lactose fermenting organisus into the four following groups: I-those which do not ferment either saccharose or dulcit, II-those which ferment dulcit but not saccharose, III-those which ferment both dulcit and saccharose, and IV - those which ferment saccharose but not dulcit. Of itself, this laboratory classification is 
of little value, unless we can say that one or other of the groups is characteristic of human or animal excreta, or better still if we can split the groups further into individual species for separate study as to their sanitary significance. Macl'onkey's work suggests that groups I and II are more common in human fæeces, and groups I and IV in animal excrement; that is in England. Speaking from personal experience we are inclined to think that those which ferment dulcit but not saccharose are the more fæcal type, but the group is not entirely composed of these objectionable varieties. Does the rile hold good for India? We do not know, beyond that Clemesha's work in Madras is suggestive that it does hold good. On this point we want more investigations, coupled with further work to determine whether the rule applies for all seasons of the year. Clemesha, Aiyar and Mudaliyar hint that the actial flora of both human and animal fæces varies considerably at different times of the year, and that corresponding changes in the bacterial contents of natural Indian waters occur. The importance of know. ing exact details as to these seasonal variations in both excrement and water are obvious".

The following is also quoted:-

"A good well or spring water should contain no fæcal bacilli in 15 c. c., while can indifferent or usable water should contain no fæcal bacilli in $20 \mathrm{c}$. c. The presumptive evidence of fæcal bacilli is drawn from the initial reactions in the lactose bile-salt broth cultures, Furtlier, a good water from these sources should yield a total colony count of under 50 per cubic centimetre.

Pond, tank or lake waters should be condemned if they contain micro organisms of the Madras Class $I$ in 1 c. c., or less. These are very difficult viaters to judge. and much importance must be laid on the result of a critical personal inspection of the surrounding conditions, that is whether there is obvious evidence of fouling from local habitations, or the recent occurrence of rain. Incidentally, it may be remarked that the presence or absence of $\mathrm{B}$. lactis ærogenes is a valuable criterion, and the marked absence or scarcity of this particular micro-organism from waters of this class is to be taken as an indication for condemnation. Where a surface water contains more than 5 fæsal micro-organisms to the c. c, even if of the more resistant kind as included in the Madras Class III, it must be regarded with sus. picion. A fair or usable pond water should not yield more than 200 organisms per c. c. on the total count. It should show no lactose fractors in less than 5 c. c., while a desirable feature is the considerable presence of $B$. lactis ærogenes. As a rule, the less resistant type of bacteria, as grouped in the Madras Class I, should not be present in less than 15 or 20 c. c. On the other hand, a good pond water may be takell to be one which contains less than 100 total colonies per c. c. It should show no lactose fractors in 15 or $20 \mathrm{c} \mathrm{c}$, be rich in $B$. lactis ærogenes and practically devoid of the Madras Class I group in 50 cubic centimetres.

River waters are notoriously variable. A bad river water will yield as many as 1,000 colonies on total agar count. The lactose fractors will be anything from 20 to 100 ner c. c. The class of water needs to be condemned. A usable river water may be taken to be one which gives 200 to 300 colonies on the total agar count per c. c. The fæcal organism should not exceed 2 to the c. c. and should be mainly of the more resistant varieties or those in the Madras Classes II and III. If any of the less resistant type are presint or those of Class I, they should not be found in less than 15 cubic contimetres.

A good river water will not contain more than 100 colonies on total count on agar. If fæcal organisms are present they should mainly of the Marlras Classes II and III. Those of Class I should not be present in less than 50 cubic centimetres."
The whole memorandum published by Colonel Firth is well worth perusal.

\section{LEUCODERMA IN DARK RACES.}

IN the Polyclinic, September 1910, the veteran Sir Jonathan Hutchinson discusses the subject of Leucoderma or acquired piebald skin. He dis. cusses the question of these white patches being aggressive or not and decides that the majority of cases are so. Hehra said that leucoderma usually began in adult life, but cases are certainly seen in early childhood. It is suggested that leucoderma areata is only a congenitally piebald skin and that the white patches have been potentially present from birth, and only made evident by the pigment of the skin increasing during adult life. This is a matter worth observing in children of natives of India, that is to say, the skin in these cases may be already occupied by a pattern which is not visible until it is made conspicuous by morbid changes. Sir Jonathan says that it is perhaps too hastily assumed that these white patches are always aggressive, e.g., the portrait of leucoderma given in the Atlas of the New Sydenham Society was examined ten years after the picture was made and Sir Jonathan found "little or no change in the form or size of the patches beyond such as might be referred to the growth of the boy." He adds that leucodermic patches "always become more conspicuous in summer" and vary with the state of the health of their subject.

There is no doubt that this affection, often wrongly confounded with leprosy and therefore dreaded, is a very common complaint in India, where, of course, it is very conspicuous on the dark skins and in less covered by clothing in many cases.

Its rtiology is unknown and it is usually considered a trophoneurosis. We have frequently seen very extreme cases where practically the whole body had become as white as snow. Castellani and Chalmers (Tropical Medicine, p. 1143) give a good account of the disease, indeed their chapters on skin diseases in the tropics are the best we know dealing with this hitherto too little studied side of the diseases of the tropics. They state that such white patches often appear after an injury, a burn or too strong caustication. The hands and face and legs often become more or less symmetrically affected, and patches, they tell us, slowly enlarge and coalesce. There is no change of sensation and no anæsthesia in the white patches, but there is often hyperæsthia to heat and light stimulation. The disease when of considerable extent must be distinguished from albinism. There is an allied disease called Melong or Beta which has been described by Ziemann as com-
mon among West African negroes.

We would welcome any information on the prevalence of this disease among Iudians. 


\section{PARASITIC GRANULOMA.}

UNDER this name Dr. Ferguson and Mr. Owez Richards of the Egyptian Medical School have an article of much interest in Annals of Tropical Medicine, etc. (Liverpool, Vol. IV, No. 2, July 1910). The disease is described as - "a chronic elevated patch or warty growth in the skin, sharply localised and unaccompanied by other symptoms ...... a warty and a tlat form" and in their bodies "of the same class as those described in Oriental sore" have been found.... These cases are well known and have been variously called in Egypt papilliferous degeneration of theskin ; "pseudo-epithelioma;" "granuloma of foot;" "false elephantiasis ;" "fungating granuloma," names which not inaptly describe the outward appearances of the disease. It affects adults chiefly; it may be single or multiple; it is probably anto-inoculated by scratching. The infection is probably through the skin, and the rate of progress is essentially slow. The authors describe the flat and the warty form in detail and give cases one by Capt. M. F. White, I.M s., from Bushire, Persian Gulf. The facts reported are summarised as follows :-

(1) Certain forms of skin affection caused by Leishmania tropica [Leishman-Donovan bodies] occur not infrequently in Egypt.

(2) They may be solitary or multiple (latter due to anto-inoculation.)

(3) They consist essentially of a mononuclear infiltration of the subcutaneous tissues, which harbour sometimes large number of the parasites.

(4) The lesions manifest themselves clinically under two forms; the one a slightly raised, smooth flat patch; the other a prominent warty growth. They run a chronic course, and are accompanied by constitutional disturbance.

(5) They are best treated by excision and skin grafting.

The relation between the so-called "bodies" found in certain oriental sores and in this Egyptian granuloma and the serious constitutional disease known as Kala-azar is often talked about, but we know of no attempt to explain the extraordinary differences in the resulting infection. The identity has not been established for certain, morphologically no doubt they are very alike.

\section{PELLAGRA.}

WE still await anything like a proof of Dr. Sambon's theory as to the origin of pellagra. It is known that this versatile writer expressed his opinion some five years ago that pellagra was caused by some protozoal parasite, which was transmitted by some blood-sucking insect. Such a theory was very easy to formulate and the following résumé of the arguinents in favour of such a view are well summarised in a report by Dr. C. H. Lavinder of the U. S. Marine Huspital Service, who writes as follows :-
"Pellagra is not due to maize either good or bad because-

(1) It is found in places where maize is neither cultivated nor eaten (? where).

(2) It is absent from many places where maize is the staple food of the population.

(3) It has in many places either decreased or become more prevalent, without any change in the food of the people.

(4) Its constant and peculiar distribution does not agree with the very irregular and ever changing distribution of spoiled maize.

5. In over a century and a half, since the maize theory was first suggested, no one has been able to prove it.

The belief that the disease has everywhere followed the introduction of corn cultivation is unfounded. Pellagra was first recognized as a specific disease in the beginning of the eighteenth century, but this does not prove that it was not prevalent long before that time.

Pellagra is a parasitic disease because-

1. For years the person affected may present some seasonal recurrences, which can only be explained by a parasitic agent with alternating periods of activity and latency.

2. It shows a constant and characteristic topographic distribution.

3. It shows a definite seasonal incidence.

4. Its symptoms, course, duration, moroid anatomy, as well as its therapy, are similar to those of parasitic diseases.

5. Of two places, almost contiguous, one may be affected, the other not.

Pellagra is an insect-borne disease because-

1. It is limited, like malaria, sleeping sickness, etc., to rural places and more especially to the vicinity of certain water bodies.

2. It has a definite seasonal incidencespring and autumn.

3. It affects, to a large extent, a certain class of people-the field labourers.

4. It is not contagious and neither food nor water can account for its peculiar epidemiology.

5 . Within its endemic centres it affects all ages and frequently whole families.

6. Outside its endemic centres only adults who have visited the infection areas present the disease and frequently only one or two members in a family are affected.

Pellagra is conveyed by Simulium reptans because-

1. Simulium is found in the torrents and swift running streams of all pellagra districts.

2. Simulium has the peculiar seasonal distribution of pellagra (spring and autumn).

3. Simulium is found only in rural districts. It is unknown in towns and villages. It does not enter houses.

4. Simulium explains most admirably the peculiar limitation of the disease to field labourers.

5. Simulium is the only blood-sucking insect which the British field commission has found in 
its visits to numerous pellagrous districts in Italy.

6. Simulium reptans, like Anopheles maculipennis, has a world-wide distribution and explains the wide distributions of pellagra. It is found wherever pellagra is found.

7. Simulium causes epizootics in animals in America and in Europe.

8. Professor Mesuil has found a protozoal organism in simulium."

So far so good, but proof is still wanting.

\section{THE FAR EASTERN ASSOCIATION OF TROPICAL MEDICINE.}

The July issue (vol. v, 2) of the Philippine Journal of Science is full of interest as it contains many of the papers read at the first biennial meeting of the Far Eastern Association of Tropical Medicine held at Manila in March 1910.

The first paper is by Drs. A. J. McLaughlin and V. L. Andrews on infantile mortality among the Filipinos in Manila. There is a wonderful difference in the death-rate of the natives of the Island and of its imported inhabitants, e.g., Filipino death-rate over 47, Spaniards 12, Americans 13, other Occidentals 14, Chinese 16. This enormous death-rate among the Filipinos is due to the enormously high infant-deathrate, or 48 per cent. of all deaths are in children under 1 year of age. The disease causing this high rate of mortality are first and for foremost beri-beri (so called " infantile"), cholera, pueumonia, and in a lesser degree meningitis, enterocolitis, and other diseases.

This so-called "infantile beri-beri" was first described in 1898 and 1900 by Hirota of Tokyo, and the term seems to have been loosely used by native practitioners for various forms of morasmous, but true cases have the following symptoms, etc., child apparently well nourished and plump-skin anæmic, face full and swollenlimbs flabby - and at present-muscles anæmic, fat œdema, scites, pericordial sac full of fluid, right heart cavity enlarged, musculature course and firm-internal organs generally congested. Three principal symptoms, dilated and hypertrophied right heart, congestion of viscera and anasarca. Nearly all the children examined were breast fed under two months of age and had not taken rice or any artificial food. In Manila among the Filipinos 87 per cent. of the infants who die of "convulsions" and of "beriberi" are breast fed and the deaths of breast fed children from 73 per cent. of the total infant mortality. Facts which show us that the word 'breast fed' will not account for the avoidance of infantile complaints. The fact among the Filipinos is that the mother's milk is very poor milk, the mothers are underfed. The improvement of the physical condition of the Filipino mother is, therefore, an urgent question.
The next paper is one on the relationship of food to physical development by Capt. D. McCay, I.M.s., which is a résumé of his wellknown work on the metabolism of Bengalis.

Dr. V.G. Heiser has an interesting paper on many unsolved health problems, which are, however, not as he calls them "peculiar to the Philippines." Plague has not yet appeared in these islands in spite of their proximity to China, but special precautions against its importation are wisely in force. Cholera, however, is practically endemic, and it constantly appears in sporadic outbreaks.

Mr. H. M. Neeb has au article on parthenogenesis of the female crescent body. The parthenogenesis of the tertian gamete is very important as if true it gives a natural explanation of relapses of malaria in persons who have long left the tropics.

Mr. G. Slibayama described malarial parasites in the orang-outang, and Dr. J. M. Atkinson has a good article on the well worn subject of malarial fever during the puerperium. Dr. Atkinson considers that malarial fever is more likely to produce abortion than the use of quinine and in the fever season he always prescribes small (2 grains) dose of quinine to pregnant women, he says, that the medical men of Hongkong agree that the ekbolic action of quinine is very slight.

Dr. Castellani has an article on tropical bronchomycosis, which is due to a new oidiumlike fungus, not rare in Ceylon, and which is not the same disease as described by him in his Tropical Medicine (p. 921). $\mathrm{He}$ and $\mathrm{Dr}$. A. J. Chalmers also described a new intestinal ftagellate in man found in cases of what they call "Aychylostomiasis" but which others who are not purists are content to still call ankylostomiasis. Major A. Hooton, I.M.S., who represented India at this meeting, read an excellent paper on the clinical aspects of mycetoma and a sort of corn or callosity which complicates the disease. Major Leonard Rogers, J.M.s., has also written on the prevention of liver abscess by the proper use of ipecacuanha, a subject recently fully dealt with in these columus. Dr. W. E. Musgrove has an interesting note on a study of fifty fatal cases of intestinal ancebiasis without diarrhœa. THE Records of Indian Museum ( $\mathrm{Vol} . \mathrm{V}$, pt.
3, Sept. 1910), is an excellent number, but
the only article of special interest to medical the only article of special interest to medical men is the note on the larva of the Toxorhynchites immisericors (Wlk.), by Mr. C. A. Paiva, of the Indian Museum. A census of Calcutta mosquitoes is being made in the Museum and the larve of the above mosquito are found very common in the outskirts of Calcutta The interesting point is that the larvæ of $T$. immisericors feeds greedily on the larvæ of Stegomyia and as S. fasciata, the yellow fever mosquito, is very common, in earthen pots 
around Calcutta one may assume that the $T$. immisericor's may prove a useful ally in case the Panama Canal ever lets yellow fever attack India.

Dr. S. 'T. Darling, Chief of the Laboratory of the Isthmian Canal Commission, Panama, has published a valuable contribution to the literature of malaria in a pamphlet modestly entitled!Studies in Relation to Malaria (Washington Govt. Printing Office, 1910.)

He first decribes the 11 species of anophelines which has been recognised in the canal zone and a complete description follows. The best method of keeping and of breeding out mosquitoes is detailed and descriptions are given of biting ar,d infecting experiments, the estimates of gametes and the care of mosquitoes after biting are then described. The account of the malarial parasite in the mosquito is excellent and details of the experiments made are given. It is concluded that $\mathrm{A}$. albimanus a very hardy mosquito is the transmitter of rstivo-autumnal and of tertian malaria in the canal zone.

WE have not here space to abstract much that is valuable in this very complete pamphlet. We note that mesh screoning 16 holes to the inch is recommended against anophelines, but it would not be absolutely safe against Steogomiya calopus. There are some valuable notes on the effect of quinine on the parasite in the mosquito and in man. The note on latent malaria is also useful. We strongly recommend this valuable pamphlet to all workers on malaria.

Colonel L. A. WADDell, C.B., C.I.E., I.M.S. (retd.), has contributed to the Asiatic Quarterly (Oct. 1910), an interesting note on ancient Indian anatomical drawings preserved in Tibet. A set of these drawings which Colonel Waddell found in Lhasa are now deposited in the India Office Library along with about 1,000 other books and manuscripts brought from Lhasa.

Major LeonaRd Rogers, M.D., F.R.C.P., has now in the press a practical monograph on the treatment of cholera.

OUn readers will have read with much interest Major L. Rogers' able and well reasoned article in the British Medical Journal (Sept. 24th, 1910), entitled "a simple curative treatment of cholera." This method has been wonderful success in Calcutta, and we hope that it will be widely used in other parts of India.

THE Journal of 'Tropical Medicine (Sept. 15th and October 1st, 1910), contained the report of
Dr. L. Sambon on Pellagra, we have in another column given a summary of the evidence brought forward.

T'HIs is the day of the child. All lovers of children, students of child life and workers for child welfare will welcome the new and thoroughly representative journal THe CHILD, the first number of which has just appeared. Dr. T. N. Kelynack has undertaken the editorial oversight and is being assisted by a large staff of medical, educational and philanthropic experts. The first number contains communications from such well-known authorities as the Bishop of Ripon, the Earl of Meath, the Right Hon. Johı Burns, M.P. ; Sir Lauder Brunton, M.D.; Prof. H. Griesbach, Dr. A. Mathieu, President Stanler. Hall, LL.D.; Sir James Yoxall, Rev. Arthur E. Gregory, D.D.; Miss 'Temple Orme, LL.D.; J. Lew is Paton, M.A.; Rev. W. T. A. Barber, D.D.; and many others. Leaders is: all branches of child study in this and other lands are among the contributors. THe CHILD provides a much-needed medium for the co-operations of workers and an organ for the co-ordination of work relating in any way to child betterment.

\section{gequielus.}

\section{"A Treatise on Materia Medica and Thera.} peutics."-By Rakhaldas GHosh, L.M.s., Cal. University. Fourth Edition. Edited by Lt.-Col. J. T. Calvert, M.B., M.R.C.P., I.M.S., Professor of Materia Medica, Medical College, Bengal. Published by Messrs. Hinton \& Co., Calcutta. Price, Rs. 5.

No't much need be said about a book which has reached its fourth edition in a few years, and which has been very favourably reviewed in our pages on previous occasion. The book is undoubtedly one eminently suited for the needs of the local practitioners and officers in charge of isolated dispensaries, whilst the student who has thoroughly read its contents need fear no local examination. The work contains chapters on pharmacy, dispensing, pharmacology and administration of drugs. The chapters on pharmacy and dispensing are amongst the best in the book, and will be found particularly useful for compounders and dispensers. In the present edition the process of revision appears to bave been carefully carried out, and the whole work brought up-to-date. We should like to see a copy of this book in the hands of the medical officers of all localfund dispensaries, whose only literature is too often a copy of the British pharmacopœia, which is almost out of date by the time it leaves the printer's hands. Printed on excellent paper with few typographical errors and with an attractive binding, it is a credit to the Calcutta publishers. 